\title{
Management of patients with valvular and non-valvular atrial fibrillation in Poland: Results from Reference Cardiology University Center
}

\author{
Paulina Łopatowska, Anna Tomaszuk-Kazberuk, Elżbieta Młodawska, \\ Hanna Bachórzewska-Gajewska, Jolanta Małyszko, \\ Sławomir Dobrzycki, Włodzimierz J. Musiał \\ ${ }^{1}$ Department of Cardiology, Medical University in Bialystok, Poland \\ ${ }^{2}$ Department of Invasive Cardiology, Medical University in Bialystok, Poland \\ ${ }^{4}$ Department of Nephrology, Medical University in Bialystok, Poland \\ ${ }^{5}$ Department of Clinical Medicine, Medical University in Bialystok, Poland
}

\begin{abstract}
Background: Information on epidemiology of atrial fibrillation $(A F)$ in Middle European Countries such as Poland is limited.

Methods: We studied 1,556 patients with AF. We focused on different types of AF in terms of clinical features and management.

Results: $\mathrm{CHA}_{2} D S_{2}$-VASc score was $3.5 \pm 1.7$ and HAS-BLED score $-2.4 \pm 1.1$. In-hospital mortality was $2 \%$. The $\mathrm{CH}_{2} D S_{2}$-VASc score was the highest in permanent $A F(p<0.001)$ and the HAS-BLED score was the highest in paroxysmal and permanent $A F(p<0.001)$. The $\mathrm{CHA}_{2} D S_{2}$-VASc score $\geq 2$ was found in the majority of non-valvular AF patients. Permanent $A F$ was associated with the highest thromboembolic risk $(p<0.001)$. Valvular $A F$ was more commonly observed in patients with permanent $A F(p=0.004)$. Seventy-one percent of $p a-$ tients who had $\mathrm{CH}_{2} D S_{2}$-VASc $>2$ received antithrombotic therapy. Acetylsalicylic acid alone was most common in paroxysmal $A F(p<0.001)$. Patients with valvular $A F$ had more often permanent $A F(p<0.004)$. Valvular $A F$ patients were more often prescribed antithrombotic therapy ( $p=0.001)$. The in-hospital mortality did not differ between patients with valvular and non-valvular $A F(p=0.3)$. In multivariate logistic regression, odds of in-hospital death were higher for patients $>75$ years old $(O R=6.26, p=0.001,95 \%$ CI 2.06-19.02) and with ejection fraction $<35 \%(O R=5.25, p<0.001,95 \%$ CI 2.24-12.32).

Conclusions: Our population with AF have similar risk of stroke and bleeding as in European registries. The need for anticoagulation in AF patients is well established in daily medical care in Poland similarly to Western Europe. Patients with valvular AF are more frequently prescribed antithrombotic therapy than patients with non-valvular AF. In-hospital mortality is relatively low in both valvular and non-valvular AF patients and is connected with old age and diminished ejection fraction. (Cardiol J 2015; 22, 3: 296-305)
\end{abstract}

Key words: valvular atrial fibrillation, non-valvular atrial fibrillation

Address for correspondence: Anna Tomaszuk-Kazberuk, MD, PhD, Department of Cardiology, University Hospital in Bialystok, ul. Skłodowska-Curie 24A, 15-276 Białystok, Poland, tel: +48 85746 86 56, fax: + 48857468604 , e-mail: walkaz@poczta.fm

Received: 24.07.2014 Accepted: 21.09.2014 


\section{Introduction}

Atrial fibrillation $(\mathrm{AF})$ is the most common cardiac arrhythmia, occurring in $1-2 \%$ of the general population and is a well known risk factor of cardiovascular morbidity and mortality [1]. In 2010 and 2012, the guidelines of the European Society of Cardiology on the management of AF were released as a consequence of well controlled randomized trials such as RELY, ROCKET and ARISTOTLE [1-5]. On the other hand, there is an increasing number of national registries describing prevalence of AF, co-morbidities, stroke risk factors and antithrombotic therapy in real life conditions $[6,7]$. Data from 7 representative Western European countries illustrating changes in the management of AF have been recently published [8]. Information on epidemiology of AF in Middle European Countries such as Poland is limited. Moreover, data on valvular $\mathrm{AF}$ patients are very scant.

This is the first real life report on characteristics and management of the patients with $\mathrm{AF}$ including valvular AF patients from Reference Cardiology University Center in Bialystok, Poland.

\section{Methods}

\section{Study population}

We retrospectively studied 1,556 patients with the diagnosis of AF hospitalized in the Department of Cardiology and Department of Invasive Cardiology in years 2012-2014. No exclusion criteria were defined to avoid biased selection of patients and achieve a cohort close to real life. At the study entry medical history was recorded, all patients underwent physical examination, resting electrocardiography (ECG), and routine transthoracic echocardiography. The study protocol conformed to the ethical guidelines of the 1975 Declaration of Helsinki, and was approved by the local Ethics Committee.

In the analysis, we focused on different types of $\mathrm{AF}$ in terms of clinical features and management.

\section{Definitions of valvular AF, chronic kidney disease, chronic heart failure, anemia and ischemic heart disease}

We define valvular AF according to recent 2014 AHA/ACC/HRS guideline for the management of patients with $\mathrm{AF}$ [9] as AF in rheumatic mitral stenosis, a mechanical or bioprosthetic heart valve or valve repair.

Chronic kidney disease (CKD) was defined as estimated glomerular filtration rate $(\mathrm{eGFR})<60 \mathrm{~mL} /$ $/ \mathrm{min} / 1.73 \mathrm{~m}^{2}$.
The group with heart failure $(\mathrm{HF})$ consistent of patients with ejection fraction $(\mathrm{EF})<50 \%$.

Anemia was defined as hemoglobin concentration less than $13 \mathrm{mg} / \mathrm{dL}$ in males and $12 \mathrm{mg} / \mathrm{dL}$ in females.

Ischemic heart disease (IHD) was defined as significant stenosis on coronary angiography or history of myocardial infarction (MI).

\section{Statistical analysis}

Data are expressed as means and standard deviations. Relative frequencies are used to present categorical variables. The Student's t-test or the Wilcoxon rank-sum test was used for statistical analysis where applicable. The Kruskal-Wallis test or $\chi^{2}$ test were used to describe differences between different types of AF. Logistic regression and multinomial logistic regression was used to evaluate the association between variables and in-hospital mortality. A p value of less than 0.05 was considered statistically significant. The statistic software, StataIC (data analysis of statistical software) version 13 , was used.

\section{Results}

\section{Baseline characteristics}

A total of 1,556 patients with $\mathrm{AF}$ ( 700 women, $45 \%$; mean age $71 \pm 11$ years) were included in the analysis. Paroxysmal AF was present in $42 \%$ $(\mathrm{n}=659)$, persistent in $17 \%(\mathrm{n}=260)$, permanent in $41 \%(\mathrm{n}=637)$ of the patients. Valvular AF was observed in $5 \%(\mathrm{n}=71)$. Hypertension was present in $74 \%(\mathrm{n}=1,145)$, diabetes in $27 \%$ $(\mathrm{n}=415)$, CKD in $31 \%(\mathrm{n}=474)$, IHD in $45 \%$ $(n=706)$ and chronic HF in $56 \%(n=877)$ of the patients. The mean left ventricular EF assessed by echocardiography was $46 \pm 14 \%$, mean left atrium diameter was $45 \pm 8 \mathrm{~mm}$.

$\mathrm{CHA}_{2} \mathrm{DS}_{2}$-VASc (congestive heart failure, hypertension, age $\geq 75$, diabetes mellitus, prior stroke or transient ischemic attack, vascular disease, age 65 to 74, female) score in the population with non-valvular AF was $3.5 \pm 1.7$ and HAS-BLED (hypertension, abnormal renal/liver function, stroke, bleeding history or predisposition, labile international normalized ratio [INR], elderly, drugs/ /alcohol concomitantly) score was $2.4 \pm 1.1$.

In the study population, the in-hospital mortality was $2 \%(\mathrm{n}=35)$, there were no differences between males and females $(\mathrm{p}=0.07)$.

Clinical characteristics of the population and gender differences are shown in Table 1. 
Table 1. Clinical characteristics of the population and gender differences.

\begin{tabular}{|c|c|c|c|c|}
\hline & All patients ( $n=1,556)$ & Female $(n=700)$ & Male $(n=856)$ & $\mathbf{P}$ \\
\hline Age [years] & $71 \pm 11$ & $74 \pm 9$ & $69 \pm 12$ & $<0.001$ \\
\hline Age $\geq 75$ years $[\%]$ & 43 & 35 & 52 & $<0.001$ \\
\hline Body mass index $\left[\mathrm{kg} / \mathrm{m}^{2}\right]$ & $29 \pm 5$ & $29 \pm 5$ & $29 \pm 5$ & 0.4 \\
\hline Heart rate $[\mathrm{bpm}]$ & $81 \pm 26$ & $82 \pm 25$ & $81 \pm 24$ & 0.3 \\
\hline Bradycardia (< 60 bpm) & 14 & 14 & 14 & 0.7 \\
\hline Tachycardia (> 100 bpm) & 16 & 16 & 17 & 0.5 \\
\hline $\mathrm{SBP}[\mathrm{mm} \mathrm{Hg}]$ & $130 \pm 23$ & $131 \pm 24$ & $130 \pm 21$ & 0.4 \\
\hline $\mathrm{CHA}_{2} \mathrm{DS}_{2}$-VASc score: & 3.5 & $4.3 \pm 1.5$ & $2.9 \pm 1.6$ & 0.001 \\
\hline $0[\%]$ & 3 & 0 & 5 & $<0.001$ \\
\hline $1[\%]$ & 10 & 3 & 16 & $<0.001$ \\
\hline$\geq 2[\%]$ & 87 & 97 & 79 & $<0.001$ \\
\hline HAS-BLED score: & 2.4 & $2.5 \pm 1$ & $2.3 \pm 1.1$ & 0.001 \\
\hline $0[\%]$ & 10 & 5 & 14 & $<0.001$ \\
\hline$\geq 3[\%]$ & 25 & 18 & 33 & $<0.001$ \\
\hline eGFR $\left[\mathrm{mL} / \mathrm{min} / 1.73 \mathrm{~m}^{2}\right]$ : & $74 \pm 26$ & $72 \pm 28$ & $75 \pm 24$ & 0.02 \\
\hline$\geq 90[\%]$ & 29 & 32 & 26 & 0.003 \\
\hline $60-89[\%]$ & 40 & 40 & 39 & \\
\hline $45-59[\%]$ & 17 & 16 & 18 & \\
\hline $30-44[\%]$ & 10 & 9 & 11 & \\
\hline $15-29[\%]$ & 3 & 2 & 5 & \\
\hline$<15[\%]$ & 1 & 1 & 1 & \\
\hline Left atrial diameter [mm] & $45 \pm 8$ & $44 \pm 8$ & $46 \pm 8$ & 0.0004 \\
\hline Ejection fraction [\%] & $46 \pm 14$ & $49 \pm 13$ & $42 \pm 14$ & $<0.001$ \\
\hline Valvular AF [\%] & 5 & 4 & 6 & 0.08 \\
\hline Type of AF: & & & & 0.0004 \\
\hline Paroxysmal [\%] & 42 & 38 & 48 & \\
\hline Persistent [\%] & 17 & 18 & 15 & \\
\hline Permanent [\%] & 41 & 44 & 37 & \\
\hline \multicolumn{5}{|l|}{ Co-morbidity: } \\
\hline No co-morbidity [\%] & 3 & 2 & 3 & 0.3 \\
\hline 1 co-morbidity [\%] & 12 & 11 & 12 & 0.5 \\
\hline$\geq 2$ co-morbidity [\%] & 85 & 86 & 84 & 0.3 \\
\hline Hypertension [\%] & 74 & 70 & 78 & $<0.001$ \\
\hline Diabetes mellitus [\%] & 27 & 24 & 30 & 0.007 \\
\hline Ischemic heart disease [\%] & 45 & 48 & 42 & 0.03 \\
\hline Chronic heart failure [\%] & 56 & 55 & 58 & 0.2 \\
\hline Ejection fraction $<35 \%$ & 25 & 32 & 16 & $<0.001$ \\
\hline Dilated cardiomyopathy [\%] & 7 & 11 & 2 & $<0.001$ \\
\hline Chronic kidney disease [\%] & 31 & 28 & 35 & 0.002 \\
\hline COPD [\%] & 7 & 8 & 4 & $<0.001$ \\
\hline Anemia [\%] & 29 & 28 & 29 & 0.9 \\
\hline Hypothyroidism [\%] & 3 & 2 & 5 & 0.002 \\
\hline Hyperthyroidism [\%] & 2 & 2 & 3 & 0.01 \\
\hline Peripheral artery disease [\%] & 3 & 4 & 1 & $<0.001$ \\
\hline Previous MI [\%] & 18 & 20 & 15 & 0.006 \\
\hline Previous TIA/stroke [\%] & 10 & 10 & 10 & 0.7 \\
\hline Previous PCI [\%] & 9 & 11 & 6 & 0.001 \\
\hline Previous CABG [\%] & 6 & 7 & 4 & 0.006 \\
\hline Pacemaker [\%] & 15 & 13 & 18 & 0.004 \\
\hline ICD/CRT [\%] & 5 & 7 & 2 & $<0.001$ \\
\hline Electrical cardioversion [\%] & 6 & 7 & 5 & 0.9 \\
\hline \multicolumn{5}{|l|}{ Pharmacological cardioversion: } \\
\hline Amiodarone [\%] & 4 & 4 & 3 & 0.5 \\
\hline Propafenone [\%] & 1 & 1 & 1 & 0.7 \\
\hline In-hospital mortality [\%] & 2 & 2 & 3.2 & 0.07 \\
\hline
\end{tabular}

AF — atrial fibrillation; CABG - coronary artery bypass graft; COPD — chronic obstructive pulmonary disease; CRT — implanted cardiac resynchronization device; eGFR — estimated glomerular filtration rate; ICD — implantable cardioverter defibrillator; MI — myocardial infarction; $\mathrm{PCl}$ - percutaneous coronary interventions; SBP — systolic blood pressure; TIA — transient ischemic attack 


\section{Prevalence of co-morbidities in different types of $\mathrm{AF}$}

Out of 1,556 patients, $3 \%$ were diagnosed to have only AF with no co-morbidity, $12 \%$ had one co-morbidity and $85 \%$ two or more co-morbidities. Among patients without co-morbidities or with one co-morbidity, paroxysmal type of AF was prevalent $(p=0.003, p=0.006$, respectively).

The $\mathrm{CHA}_{2} \mathrm{DS}_{2}$-VASc score in non-valvular $\mathrm{AF}$ population was the highest in permanent type of $\mathrm{AF}$ $(\mathrm{p}<0.001)$ and the HAS-BLED score was the highest in paroxysmal and permanent $\mathrm{AF}(\mathrm{p}<0.001)$.

We observed several significant differences between patients with paroxysmal and permanent AF. Those with paroxysmal type had higher eGFR, smaller left atrium $(\mathrm{p}<0.001)$, higher $\mathrm{EF}(\mathrm{p}<0.001)$, less patients with $\mathrm{HF}$ with $\mathrm{EF}<35 \%(\mathrm{p}<0.001)$, less patients with valvular AF ( $\mathrm{p}=0.004)$.

Clinical characteristics of patients with different types of $\mathrm{AF}$ are shown in Table 2.

\section{The cause of admission}

The more common cause of admission were scheduled procedures (62\%, coronary angiography, ablation and pacemaker implantation), less frequently acute coronary syndromes (14\%). Among patients with MI paroxysmal type of AF was most common $(p<0.001)$. Permanent AF was more often observed in patients admitted due to exacerbation of chronic HF ( $p<0.001)$ (Table 3 ).

\section{Stroke risk factors}

The $\mathrm{CHA}_{2} \mathrm{DS}_{2}$-VASc score $\geq 2$ was found in the majority of non-valvular AF patients. Permanent type of $\mathrm{AF}$ was associated with the highest thromboembolic risk $(\mathrm{p}<0.001)$ and was most commonly observed in patients with valvular $\mathrm{AF}$ $(\mathrm{p}=0.004)($ Table 4$)$.

\section{Antithrombotic therapy at discharge}

Out of $1,537(99 \%)$ patients who had $\mathrm{CHA}_{2} \mathrm{DS}_{2^{-}}$ -VASc score $\geq 2.71 \%$ received antithrombotic therapy. Among patients who did not require anticoagulation $\left(\mathrm{n}=19, \mathrm{CHA}_{2} \mathrm{DS}_{2}\right.$-VASc score $\left.=0\right)$ 7 received oral anticoagulation.

Antiplatelet drug was given in $39 \%$ of the patients. Out of this group $21 \%$ of patients had both acetylsalicylic acid (ASA) and oral anticoagulation and $18 \%(\mathrm{n}=277)$ ASA as the only antithrombotic treatment. Thirty-four percent out of the population treated with ASA were diagnosed previously with IHD. ASA alone was the most common treatment in paroxysmal type of AF $(\mathrm{p}<0.001)$ (Table 5).

\section{Comparison of patients with valvular and non-valvular $\mathrm{AF}$}

Patients with valvular AF were older $(\mathrm{p}<0.001)$, had higher systolic blood pressure and INR on admission $(\mathrm{p}<0.001, \mathrm{p}=0.03$, respectively). They had more often permanent type of AF $(\mathrm{p}<0.004)$, anemia $(\mathrm{p}=0.005)$ and lower EF $(\mathrm{p}<0.001)$. The history of hypertension, IHD and previous MI was observed less frequently in valvular $\mathrm{AF}$ patients ( $\mathrm{p}=0.002, \mathrm{p}=0.006, \mathrm{p}=0.03$, respectively) but they underwent coronary artery bypass graft (CABG) more often $(\mathrm{p}<0.001)$.

The mean eGFR evaluated by MDRD formula was $74 \pm 26 \mathrm{~mL} / \mathrm{min} . / 1.73 \mathrm{~m}^{2}$ in patients with non-valvular AF and $73 \pm 28 \mathrm{~mL} / \mathrm{min} . / 1.73 \mathrm{~m}^{2}$ in patients with valvular $\mathrm{AF}(\mathrm{p}=0.002)$. CKD was observed with similar frequency $(\mathrm{p}=0.35)$.

Valvular AF patients were significantly more often prescribed antithrombotic therapy $(\mathrm{p}=0.001)$.

Comparison between the two groups is shown in Table 6.

\section{In-hospital mortality}

The in-hospital mortality did not significantly differ between patients with valvular and non-valvular $\mathrm{AF}(\mathrm{p}=0.3)$. Thirty-nine percent of the patients died of HF, $30 \%$ died of MI, $13 \%$ died of aortic stenosis, $3 \%$ died of pulmonary embolism, $3 \%$ died of stroke, $3 \%$ died of sepsis and $9 \%$ died of other reasons.

In the logistic regression model, odds of inhospital death were 4.6 times higher for patients $>75$ years old $(\mathrm{p}<0.001,95 \%$ CI $2.08-10.21)$ and 6.4 times higher if left ventricular EF was $<35 \%$ ( $\mathrm{p}<0.001,95 \%$ CI $2.84-14.41)$. Of all co-morbidities diabetes $(\mathrm{OR}=2.36, \mathrm{p}=0.012,95 \% \mathrm{CI}$ 1.20-4.64), $\mathrm{CKD}(\mathrm{OR}=2.73, \mathrm{p}=0.006,95 \% \mathrm{CI}$ 1.33-5.59) and anemia (OR $=3.11, \mathrm{p}=0.002,95 \%$ CI 1.52-6.36) were significantly associated with in-hospital mortality.

In multivariate logistic regression, odds of inhospital death were higher for patients $>75$ years old $(\mathrm{OR}=6.26, \mathrm{p}=0.001,95 \% \mathrm{CI} 2.06-19.02)$ and with $\mathrm{EF}<35 \%(\mathrm{OR}=5.25, \mathrm{p}<0.001,95 \% \mathrm{CI}$ 2.24-12.32) (Table 7).

\section{Discussion}

Recently, several population-based studies and registries have provided information on the incidence, prevalence, and outcome of $\mathrm{AF}$ population $[6,7,10-12]$. However, there are no data regarding the characteristics of AF patients in Poland. We report the first results from the Cardiology Reference Center. 
Table 2. Clinical characteristics of patients with different types of atrial fibrillation.

\begin{tabular}{|c|c|c|c|c|}
\hline & $\begin{array}{l}\text { Paroxysmal AF } \\
(n=659)\end{array}$ & $\begin{array}{c}\text { Persistent AF } \\
(n=260)\end{array}$ & $\begin{array}{l}\text { Permanent AF } \\
\quad(n=637)\end{array}$ & $\mathbf{P}$ \\
\hline Age [years] & $71 \pm 11$ & $67 \pm 11$ & $73 \pm 10$ & 0.001 \\
\hline Age $\geq 75$ years $[\%]$ & 41 & 30 & 50 & 0.001 \\
\hline Female $[\%]$ & 49 & 60 & 59 & 0.0004 \\
\hline Body mass index $\left[\mathrm{kg} / \mathrm{m}^{2}\right]$ & $29 \pm 5$ & $29 \pm 5$ & $29 \pm 5$ & 0.7 \\
\hline Heart rate $[\mathrm{bpm}]$ & $80 \pm 25$ & $88 \pm 26$ & $80 \pm 23$ & 0.001 \\
\hline Bradycardia (< 60 bpm] & 16 & 10 & 14 & 0.09 \\
\hline Tachycardia (> 100 bpm) & 17 & 22 & 14 & 0.01 \\
\hline $\mathrm{SBP}[\mathrm{mm} \mathrm{Hg}]$ & $132 \pm 23$ & $128 \pm 21$ & $130 \pm 23$ & 0.05 \\
\hline $\mathrm{CHA}_{2} \mathrm{DS}_{2}$-VASc score: & $3.5 \pm 1.7$ & $2.9 \pm 1.8$ & $3.6 \pm 1.6$ & 0.001 \\
\hline $0[\%]$ & 3 & 7 & 1 & $<0.001$ \\
\hline $1[\%]$ & 11 & 16 & 8 & 0.02 \\
\hline$\geq 2[\%]$ & 86 & 77 & 91 & $<0.001$ \\
\hline HAS-BLED: & $2.5 \pm 1.1$ & $2.0 \pm 1.1$ & $2.4 \pm 1.1$ & 0.001 \\
\hline $0[\%]$ & 2 & 8 & 3 & $<0.001$ \\
\hline$\geq 3[\%]$ & 50 & 30 & 43 & $<0.001$ \\
\hline eGFR $\left[\mathrm{mL} / \mathrm{min} / 1.73 \mathrm{~m}^{2}\right]:$ & $76 \pm 26$ & $76 \pm 26$ & $70 \pm 26$ & 0.001 \\
\hline$\geq 90[\%]$ & 31 & 30 & 27 & 0.0003 \\
\hline $60-89[\%]$ & 43 & 43 & 34 & \\
\hline $45-59[\%]$ & 13 & 14 & 23 & \\
\hline $30-44[\%]$ & 9 & 8 & 11 & \\
\hline $15-29[\%]$ & 3 & 3 & 4 & \\
\hline$<15[\%]$ & 1 & 1 & 1 & \\
\hline International normalized ratio & $1.4 \pm 1$ & $1.8 \pm 1$ & $1.7 \pm 1$ & \\
\hline International normalized ratio $>3.5$ & 3 & 7 & 6 & 0.009 \\
\hline Left atrial diameter [mm] & $42 \pm 6$ & $45 \pm 7$ & $50 \pm 9$ & 0.001 \\
\hline Ejection fraction [\%] & $49 \pm 13$ & $46 \pm 14$ & $42 \pm 14$ & 0.001 \\
\hline Valvular AF [\%] & 3 & 4 & 7 & 0.004 \\
\hline \multicolumn{5}{|l|}{ Co-morbidity: } \\
\hline No co-morbidity [\%] & 3 & 6 & 2 & 0.003 \\
\hline 1 co-morbidity [\%] & 12 & 17 & 9 & 0.006 \\
\hline$\geq 2$ co-morbidity $[\%]$ & 84 & 78 & 89 & 0.00003 \\
\hline Hypertension [\%] & 78 & 65 & 73 & 0.0003 \\
\hline Diabetes mellitus [\%] & 27 & 22 & 28 & 0.2 \\
\hline Ischemic heart disease [\%] & 49 & 34 & 46 & 0.0003 \\
\hline Chronic heart failure [\%] & 57 & 60 & 54 & 0.3 \\
\hline Ejection fraction $<35 \%$ & 17 & 24 & 33 & $<0.001$ \\
\hline Dilated cardiomyopathy [\%] & 4 & 6 & 11 & $<0.001$ \\
\hline Chronic kidney disease [\%] & 26 & 27 & 39 & $<0.001$ \\
\hline COPD [\%] & 7 & 6 & 8 & 0.6 \\
\hline Anemia [\%] & 31 & 21 & 30 & 0.006 \\
\hline Hypothyroidism [\%] & 4 & 2 & 4 & 0.4 \\
\hline Hyperthyroidism [\%] & 2 & 3 & 2 & 0.9 \\
\hline Peripheral artery disease [\%] & 4 & 2 & 3 & 0.3 \\
\hline Previous MI [\%] & 22 & 14 & 16 & 0.005 \\
\hline Previous TIA/stroke [\%] & 10 & 7 & 12 & 0.09 \\
\hline Previous $\mathrm{PCl}[\%]$ & 9 & 7 & 10 & 0.4 \\
\hline Previous CABG [\%] & 4 & 7 & 7 & 0.1 \\
\hline Pacemaker [\%] & 16 & 6 & 19 & $<0.001$ \\
\hline ICD/CRT [\%] & 3 & 5 & 7 & 0.0007 \\
\hline Electrical cardioversion [\%] & 2 & 30 & 1 & $<0.001$ \\
\hline \multicolumn{5}{|l|}{ Pharmacological cardioversion: } \\
\hline Amiodarone [\%] & 5 & 8 & 0 & $<0.001$ \\
\hline Propapafenone [\%] & 1 & 2 & 0 & 0.002 \\
\hline In-hospital mortality [\%] & 2 & 3 & 2 & 0.8 \\
\hline
\end{tabular}

Abbreviations as in Table 1. 
Table 3. The cause of admission.

\begin{tabular}{lccccc}
\hline & $\begin{array}{c}\text { All patients } \\
(\mathbf{n}=\mathbf{1 , 5 5 6 )}\end{array}$ & $\begin{array}{c}\text { Paroxysmal AF } \\
(\mathbf{n}=\mathbf{6 5 9})\end{array}$ & $\begin{array}{c}\text { Persistent AF } \\
(\mathbf{n}=\mathbf{2 6 0})\end{array}$ & $\begin{array}{c}\text { Permanent AF } \\
(\mathbf{n}=\mathbf{6 3 7 )}\end{array}$ & P \\
\hline Atrial fibrillation [\%] & 5 & 3 & 18 & 2 & $<0.0001$ \\
Acute coronary syndrome: & 14 & 17 & 10 & 12 & $<0.0001$ \\
Unstable angina [\%] & 3 & 3 & 1 & 3 & \\
NSTEMI [\%] & 6 & 8 & 5 & 5 & \\
STEMI [\%] & 5 & 6 & 4 & 4 & \\
Exacerbation of CHF [\%] & 8 & 4 & 7 & 12 & \\
Acute heart failure [\%] & 3 & 2 & 3 & 3 & \\
Pulmonary embolism [\%] & 1 & 2 & 2 & 1 & \\
Schedule procedure: & 58 & 59 & 55 & 60 & $<0.0001$ \\
Pacemaker implantation [\%] & 7 & 5 & 1 & 10 & \\
Ablation [\%] & 1 & 3 & 1 & 0 & \\
$\quad$ Coronary angiography [\%] & 51 & 51 & 53 & 50 & \\
Other [\%] & 10 & 12 & 6 & 10 & $<0.0001$ \\
\hline
\end{tabular}

CHF — chronic heart failure; NSTEMI — non ST elevation myocardial infarction; STEMI — ST elevation myocardial infarction

Table 4. Stroke risk factors.

\begin{tabular}{|c|c|c|c|c|}
\hline & $\begin{array}{l}\text { Paroxysmal AF } \\
\quad(n=659)\end{array}$ & $\begin{array}{l}\text { Persistent AF } \\
(n=260)\end{array}$ & $\begin{array}{l}\text { Permanent AF } \\
\quad(n=637)\end{array}$ & $\mathbf{P}$ \\
\hline Age $\geq 75$ years $[\%]$ & 41 & 30 & 50 & $<0.001$ \\
\hline Hypertension [\%] & 78 & 65 & 73 & 0.0003 \\
\hline Diabetes mellitus [\%] & 27 & 22 & 28 & 0.2 \\
\hline Coronary artery disease [\%] & 49 & 34 & 46 & 0.0003 \\
\hline Chronic heart failure [\%] & 57 & 60 & 54 & 0.3 \\
\hline Ejection fraction < 35\% & 17 & 24 & 33 & $<0.001$ \\
\hline Peripheral artery disease [\%] & 4 & 2 & 3 & 0.3 \\
\hline Previous MI [\%] & 22 & 14 & 16 & 0.005 \\
\hline Previous TIA/stroke [\%] & 10 & 7 & 12 & 0.09 \\
\hline $\mathrm{CHA}_{2} \mathrm{DS}_{2}$-VASc score $\geq 2$ & 86 & 77 & 91 & $<0.001$ \\
\hline Valvular AF [\%] & 3 & 4 & 7 & 0.004 \\
\hline
\end{tabular}

Abbreviations as in Table 1.

$\mathrm{AF}$ is associated with a variety of cardiovascular conditions and frequently coexists with HF, both leading to increased mortality $[7,13]$. In consequence, $\mathrm{AF}$ population remains a heterogenous group due to variety of clinical presentations and treatment options. In most of the reports and registries, $\mathrm{AF}$ is associated with at least one concomitant condition, most commonly with hypertension [6, 7]. In our population, $97 \%$ of AF patients had at least one associated medical condition. Approximately half of the AF patients suffered from coronary artery disease or HF. Every third person was obese, had diabetes or anemia. These findings are consistent with the data from Euro Heart Survey study where $90 \%$ of the patients had concomitant co-morbidities, with hypertension as the most prevalent co-morbidity [13].

Classification of AF into different types is useful in clinical practice and is associated with different therapy approach. There are only few studies showing differences in characteristics and management of patients with different types of AF [7]. In our study, the most common AF type was paroxysmal AF, similarly as in RAFTING registry from Greece 
Table 5. Antithrombotic therapy at discharge.

\begin{tabular}{lccccc}
\hline & $\begin{array}{c}\text { All patients } \\
\text { (n= 1,538) }\end{array}$ & $\begin{array}{c}\text { Paroxysmal AF } \\
\text { (n= 652) }\end{array}$ & $\begin{array}{c}\text { Persistent AF } \\
\text { (n= 257) }\end{array}$ & $\begin{array}{c}\text { Permanent AF } \\
\text { (n = 629) }\end{array}$ \\
\hline Antithrombotic therapy [\%] & 71 & 61 & 80 & P & 79 \\
Vitamin K antagonists [\%] & 59 & 49 & 59 & 70 & $<0.001$ \\
Warfarin [\%] & 27 & 26 & 33 & 25 & 0.4 \\
Acenocumarol [\%] & 32 & 23 & 26 & 45 & $<0.001$ \\
NOAC [\%] & 12 & 12 & 21 & 9 & $<0.001$ \\
Dabigatran [\%] & 5 & 4 & 12 & 3 & $<0.001$ \\
Rivaroxaban [\%] & 7 & 8 & 9 & 6 & 0.1 \\
Antiplatelet therapy [\%] & 39 & 48 & 33 & 34 & $<0.001$ \\
ASA + VKA [\%] & 19 & 18 & 20 & 21 & $<0.001$ \\
ASA + NOAC [\%] & 2 & 2 & 3 & 2 & $<0.001$ \\
ASA without OAC [\%] & 18 & 28 & 10 & 11 & $<0.001$ \\
No antithrombotic therapy [\%] & 29 & 39 & 21 & 21 & $<0.001$ \\
\hline
\end{tabular}

AF — atrial fibrillation; ASA — acetylsalicylic acid; NOAC — new oral anticoagulants; OAC — oral anticoagulation; VKA — vitamin K antagonists

[14], but in contrast to AFNET and PREFER registry were most common type was permanent type $[7,8]$. Nieuwlaat et al. [13] showed that patients with permanent $\mathrm{AF}$ were older, had more often $\mathrm{HF}$, valvular heart disease, diabetes and previous stroke/ /transient ischemic attack. There were no differences in prevalence of coronary artery disease, CKD or history of $\mathrm{MI}$ and $\mathrm{CABG} /$ percutaneous coronary intervention [13]. Consistent data were published in the Registry of German Competence NETwork on Atrial Fibrillation (AFNET) [7]. In our population, prevalence of co-morbidities, such as hypertension, diabetes, IHD, chronic HF and anemia is similar in patients with paroxysmal and permanent AF. These findings are contrary to studies mentioned above, in which paroxysmal AF population had less often concomitant conditions.

Sex differences in the epidemiology and clinical management of $\mathrm{AF}$ are evident and have been described in several studies $[6,15,16]$. In this analysis, we found that females were older, had more often IHD, severely impaired EF, previous $\mathrm{MI}$ and CABG. These results differ from the Euro Observational Research Programme on Atrial Fibrillation (EORP-AF) where females had more non-ischemic HF and HF with preserved EF [6]. Similarly in Euro Heart Survey on Atrial Fibrillation females had more co-morbidities including HF with preserved EF [17]. Secondly, in our study, female patients had more often a permanent type of AF. The prevalence of valvular AF was similar in both genders. These results also differ from the EORP-AF and Euro Heart Survey studies where valvular AF was found more frequently in females, but there were no differences in type of $\mathrm{AF}$ between males and females $[6,16]$.

To date information on valvular AF is very scant. The prevalence of valvular AF in Europe according to PREFER registry varies from $1.9 \%$ to $5.4 \%$ [8]. In our population, valvular $\mathrm{AF}$ was present in $5 \%$ of the patients, similarly as in Spain and France. Patients with valvular AF were older, had more often a permanent type of AF, anemia and lower EF. The history of hypertension, coronary artery disease and previous MI was observed less frequently in valvular $\mathrm{AF}$ patients but they underwent $\mathrm{CABG}$ more often. CKD was recorded with similar frequency. Valvular AF patients were significantly more often prescribed antithrombotic therapy. To our knowledge there have been no studies focusing on characteristics and management of patients with valvular AF so far.

Antithrombotic treatment is the hottest topic concerning AF nowadays. Our data were consistent with data from Italy, where $70 \%$ of patients were given such a therapy. Different results were reported in France, Spain and Germany where antithrombotic treatment was used in $90 \%, 87.9 \%$ and $87.4 \%$, respectively. There were no significant differences between the use of new oral anticoagulants (NOAC) between Poland (12\%), Germany (11.6\%) and Spain (11.2\%). In France, NOAC were used half as frequently. Surprisingly, in such a Western European country as Italy the rate of use of NOAC was extremely low $(0.3 \%)$, much lower than in Poland [8]. 
Table 6. Comparison of patients with valvular and non-valvular atrial fibrillation.

\begin{tabular}{|c|c|c|c|}
\hline & Non-valvular AF & Valvular AF & $\mathbf{P}$ \\
\hline Age [years] & $71 \pm 11$ & $68 \pm 9$ & $<0.001$ \\
\hline Age $\geq 75$ years $[\%]$ & 44 & 24 & 0.001 \\
\hline Female [\%] & 45 & 55 & 0.08 \\
\hline Body mass index $\left[\mathrm{kg} / \mathrm{m}^{2}\right]$ & $29 \pm 5$ & $28 \pm 4$ & 0.9 \\
\hline Heart rate $[\mathrm{bpm}]$ & $81 \pm 25$ & $83 \pm 25$ & $<0.001$ \\
\hline Bradycardia (< 60 bpm) & 14 & 12 & 0.5 \\
\hline Tachycardia (> 100 bpm) & 17 & 16 & 0.9 \\
\hline $\mathrm{SBP}[\mathrm{mm} \mathrm{Hg}]$ & $131 \pm 22$ & $128 \pm 27$ & $<0.001$ \\
\hline eGFR $\left[\mathrm{mL} / \mathrm{min} / 1.73 \mathrm{~m}^{2}\right]:$ & $74 \pm 26$ & $73 \pm 28$ & 0.002 \\
\hline$\geq 90[\%]$ & 30 & 32 & 0.4 \\
\hline $60-89[\%]$ & 40 & 32 & \\
\hline $45-59[\%]$ & 17 & 17 & \\
\hline $30-44[\%]$ & 9 & 16 & \\
\hline $15-29[\%]$ & 3 & 3 & \\
\hline$<15[\%]$ & 1 & 0 & \\
\hline International normalized ratio & $1.53 \pm 1.0$ & $2.67 \pm 1.77$ & 0.03 \\
\hline Left atrial diameter $[\mathrm{mm}]$ & $45 \pm 8$ & $54 \pm 10$ & 0.7 \\
\hline Ejection fraction [\%] & $46 \pm 14$ & $44 \pm 16$ & $<0.001$ \\
\hline Type of AF: & & & 0.004 \\
\hline Paroxysmal [\%] & 43 & 25 & \\
\hline Persistent [\%] & 17 & 15 & \\
\hline Permanent [\%] & 40 & 60 & \\
\hline \multicolumn{4}{|l|}{ Co-morbidity: } \\
\hline No co-morbidity [\%] & 3 & 3 & 0.9 \\
\hline 1 co-morbidity [\%] & 12 & 15 & 0.3 \\
\hline$\geq 2$ co-morbidity [\%] & 85 & 82 & 0.3 \\
\hline Hypertension [\%] & 74 & 58 & 0.002 \\
\hline Diabetes mellitus [\%] & 23 & 31 & 0.4 \\
\hline Ischemic heart disease [\%] & 46 & 30 & 0.006 \\
\hline Chronic heart failure [\%] & 56 & 60 & 0.4 \\
\hline Ejection fraction $<35 \%$ & 24 & 32 & 0.1 \\
\hline Dilated cardiomyopathy [\%] & 7 & 10 & 0.4 \\
\hline Chronic kidney disease [\%] & 31 & 36 & 0.35 \\
\hline COPD [\%] & 7 & 7 & 0.97 \\
\hline Anemia [\%] & 28 & 43 & 0.005 \\
\hline Hypothyroidism [\%] & 3 & 1 & 0.3 \\
\hline Hyperthyroidism [\%] & 2 & 6 & 0.6 \\
\hline Peripheral artery disease [\%] & 3 & 0 & 0.1 \\
\hline Previous MI [\%] & 19 & 8 & 0.03 \\
\hline Previous TIA/stroke [\%] & 10 & 11 & 0.7 \\
\hline Previous $\mathrm{PCl}[\%]$ & 9 & 8 & 0.8 \\
\hline Previous CABG [\%] & 5 & 21 & $<0.001$ \\
\hline Pacemaker [\%] & 15 & 22 & 0.09 \\
\hline ICD/CRT [\%] & 5 & 7 & 0.4 \\
\hline Electrical cardioversion [\%] & 6 & 4 & 0.5 \\
\hline \multicolumn{4}{|l|}{ Pharmacological cardioversion: } \\
\hline Amiodarone [\%] & 4 & 4 & 0.8 \\
\hline Propapafenone [\%] & 1 & 1 & 0.7 \\
\hline Antithrombotic therapy [\%] & 70 & 85 & 0.01 \\
\hline No antithrombotic therapy [\%] & 27 & 11 & \\
\hline Unknown [\%] & 3 & 4 & \\
\hline Vitamin $\mathrm{K}$ antagonists [\%] & 58 & 84 & \\
\hline New oral anticoagulants [\%] & 12 & 1 & \\
\hline Only aspirin [\%] & 19 & 3 & 0.001 \\
\hline In-hospital mortality [\%] & 2 & 4 & 0.3 \\
\hline
\end{tabular}

Abbreviations as in Table 1. 
Table 7. Multivariate logistic regression.

\begin{tabular}{lccc}
\hline Odds of in-hospital death & Odds ratio & 95\% confidence interval & P \\
\hline Age $\geq 75$ years & 6.26 & $2.06-19.02$ & 0.001 \\
Anemia & 1.97 & $0.84-4.59$ & 0.1 \\
Chronic kidney disease & 0.86 & $0.36-2.03$ & 0.7 \\
Ejection fraction $<35 \%$ & 5.25 & $2.24-12.32$ & $<0.001$ \\
Diabetes mellitus & 1.72 & $0.73-4.06$ & 0.2 \\
\hline
\end{tabular}

Population-based studies have indicated AF to be an independent predictor of increased late mortality [18]. Data from the Framingham study demonstrated a 1.5- to 1.9-fold risk of mortality in patients with $\mathrm{AF}$ in both males and females across a wide range of ages after adjustment for preexisting cardiovascular diseases [19].

Swedish nation-wide long-term case-control study showed the same finding in patients hospitalized with incident AF. The concomitant diseases that contributed most to an increased mortality were neoplasm, chronic renal failure and chronic obstructive airway disease. It is worth noting that none of these diseases are included in $\mathrm{CHA}_{2} \mathrm{DS}_{2}$ -VASc score [12].

The relationship between mortality and type of AF remains unclear. Actually, there is no information on connections of various types of AF with all-cause mortality. For example, Swedish registry data did not allow differentiation between paroxysmal, persistent and permanent type of AF [12]. It is likely that on follow-up some of the patients progressed to permanent type of AF. For example, in the Loire Valley AF Project, only permanent type of AF was associated with increased mortality [17]. Our data on mortality concerns only shortterm follow-up what is why the analysis of types is possible, because the percentage of patients who progressed to permanent type was low. In our population, the in-hospital mortality was $2 \%$ and did not differ between patients with valvular and non-valvular AF. Of all co-morbidities only diabetes, CKD and anemia had impact on in-hospital mortality. However, the independent predictors of death were age $>75$ years and $\mathrm{EF}<35 \%$.

\section{Limitations of the study}

We have no current data on treatment strategies for the prevention of AF. Outpatient centers did not contribute for this registry and patients cared for by general practitioners were not included. This has to be taken into account when extrapolating from these data to the general popula- tion. No patients with $\mathrm{AF}$ were admitted because of a stroke, and only $5 \%$ were admitted due to $\mathrm{AF}$. These evidences point out a selection bias, probably a referral to a Cardiology and Interventional Department of a high complexity Hospital.

Multiple logistic regression requires 10 to 15 events per variable analyzed. Since there were only 31 deaths, the model obtained is not a solid evidence.

\section{Conclusions}

$\mathrm{AF}$ originates from various substrates and, as a consequence, the $\mathrm{AF}$ population remains heterogeneous group. Most patients included in our registry have at least one comorbidity, most commonly hypertension. Our population with AF have similar risk of ischemic stroke and bleeding as in European registries. The need for anticoagulation in AF patients is well established in daily medical care in Poland, similarly to Western Europe. Patients with valvular $\mathrm{AF}$ are more frequently prescribed antithrombotic therapy than patients with non-valvular $\mathrm{AF}$. In our study, paroxysmal $\mathrm{AF}$ population is similar to permanent $\mathrm{AF}$ population while in other registries permanent $\mathrm{AF}$ population correlates with $\mathrm{HF}$ more frequently. In-hospital mortality is relatively low in both valvular and non-valvular AF patients and connected with old age and left ventricular HF.

\section{Acknowledgements}

Our study was supported by funds from Leading National Research Center in Bialystok, Poland (KNOW).

\section{Conflict of interest: None declared}

\section{References}

1. Camm J, Lip GY, Caterina R et al.; ESC Committee for Practice Guidelines (CPG). 2012 focused update of the ESC Guidelines for the management of atrial fibrillation. Eur Heart J, 2012; 33: 2719-2747.

2. Camm J, Kirchhof P, Lip GY et al. Guidelines for the management of atrial fibrillation. Eur Heart J, 2010; 31: 2369-2429.

3. Connolly SJ1, Ezekowitz MD, Yusuf S et al. RE-LY Steering Committee and Investigators. Dabigatran versus warfarin in patients with atrial fibrillation. N Engl J Med. 2009; 361: 1139-1151. 
4. Patel MR1, Mahaffey KW, Garg J et al. ROCKET AF Investigators. Rivaroxaban versus warfarin in nonvalvular atrial fibrillation. N Engl J Med, 2011; 365: 883-891.

5. Granger CB1, Alexander JH, McMurray JJ et al. ARISTOTLE Committees and Investigators. Apixaban versus warfarin in patients with atrial fibrillation. N Engl J Med, 2011; 365: 981-992.

6. Lip GY, Laroche C, Boriani $\mathrm{G}$ et al. Sex-related differences in presentation, treatment, and outcome of patients with atrial fibrillation in Europe: A report from the Euro Observational Research Programme Pilot survey on Atrial Fibrillation. Europace, 2015; 17: 24-31.

7. Nabauer M, Gerth A, Limbourg T et al. The Registry of the German Competence NETwork on Atrial Fibrillation: Patient characteristics and initial management. Europace, 2009; 11: 423-434.

8. Kirchhof P, Ammentorp B, Darius H et al. Management of atrial fibrillation in seven European countries after the publication of the 2010 ESC Guidelines on atrial fibrillation: Primary results of the PREvention oF thromboemolic events: European Registry in Atrial Fibrillation (PREFER in AF). Europace, 2014; 16: 6-14.

9. January CT, Wann LS, Alpert JS et al. 2014 AHA/ACC/HRS guideline for the management of patients with atrial fibrillation: A report of the American College of Cardiology/American Heart Association Task Force on Practice Guidelines and the Heart Rhythm Society. J Am Coll Cardiol, 2014; pii: S0735-1097(14)01740-9.

10. Chugh SS, Havmoeller R, Narayanan K et al. Worldwide epidemiology of atrial fibrillation: A Global Burden of Disease 2010 Study. Circulation, 2014; 129: 837-847.

11. Nguyen TN, Hilmer SN, Cumming RG et al. Review of epidemiology and management of atrial fibrillation in developing countries. Int J Cardiol, 2013; 167: 2412-2420.
12. Andersson T1, Magnuson A, Bryngelsson IL et al. All-cause mortality in 272,186 patients hospitalized with incident atrial fibrillation 1995-2008: A Swedish nationwide long-term casecontrol study. Eur Heart J, 2013; 34: 1061-1067.

13. Nieuwlaat R, Capucci A, Camm AJ et al. Atrial fibrillation management: A prospective survey in ESC member countries: The Euro Heart Survey on Atrial Fibrillation. Eur Heart J, 2005; 26: 2422-2434.

14. Farmakis D, Pipilis A, Antoniou A et al. Clinical profile and therapeutic management of patients with atrial fibrillation in Greece: Results from the Registry of Atrial Fibrillation to Investigate New Guidelines (RAFTING). Hellenic J Cardiol, 2013; 54: 368-375.

15. Avgil Tsadok M, Jackevicius CA, Rahme E et al. Sex differences in stroke risk among older patients with recently diagnosed atrial fibrillation. JAMA, 2012; 307: 1952-1958.

16. Dagres N, Nieuwlaat R, Vardas PE et al. Gender-related differences in presentation, treatment, and outcome of patients with atrial fibrillation in Europe: A report from the Euro Heart Survey on Atrial Fibrillation. J Am Coll Cardiol, 2007; 49: 572-577.

17. Banerjee A, Taillandier S, Olesen JB et al. Pattern of atrial fibrillation and risk of outcomes: The Loire Valley Atrial Fibrillation Project. Int J Cardiol, 2013; 167: 2682-2687.

18. Vidaillet H, Granada JF, Chyou PH et al. A population-based study of mortality among patients with atrial fibrillation or flutter. Am J Med, 2002; 113: 365-370.

19. Benjamin EJ, Wolf PA, D'Agostino RB, Silershatz H, Kannel WB, Levy D. Impact of atrial fibrillation on the risk of death: The Framingham Heart Study. Circulation, 1998; 98: 946-952. 